\title{
Caffeine inhibits paclitaxel-induced apoptosis in colorectal cancer cells through the upregulation of Mcl-1 levels
}

\author{
NIZAR M. MHAIDAT, KAREM H.ALZOUBI, SAYER I. AL-AZZAM and ALHARETH A. ALSAAD \\ Department of Clinical Pharmacy, Faculty of Pharmacy, Jordan University of Science and Technology, Irbid 22110, Jordan
}

Received March 28, 2013; Accepted October 16, 2013

DOI: $10.3892 / \mathrm{mmr} .2013 .1763$

\begin{abstract}
Colorectal cancer (CRC) cells have been previously observed to be resistant to paclitaxel-induced apoptosis by activation of the mitogen-activated protein/extracellular signal-regulated kinase (MEK)/ERK signaling pathway and increased expression of glucose-regulated protein 78 (GRP78). Caffeine, the most widely used neuroactive compound, has antiproliferative activity and the ability to induce cell cycle arrest and apoptosis. In the current study, the effect of concomitant use of caffeine on paclitaxel-induced apoptosis in CRC cells was investigated. The results revealed that treatment of Colo205 cells with varying caffeine concentrations did not induce apoptosis. Pretreatment of CRC cells with caffeine significantly inhibited paclitaxel-induced cytotoxicity by increasing the levels of the antiapoptotic Bcl-2 family member, Mcl-1. This effect was inhibited by pretreatment of Colo205 cells with the MEK-ERK chemical inhibitor, U0126. In addition to GRP78, these results indicated that Mcl-1 may be a downstream target of the MEK-ERK signaling pathway. Moreover, administration of caffeine may decrease chemotherapeutic responses to paclitaxel by the MEK-ERK mediated upregulation of Mcl-1. In conclusion, coadministration of cell cycle-modifying agents, including caffeine should be avoided in CRC patients treated with paclitaxel.
\end{abstract}

\section{Introduction}

Colorectal cancer (CRC) is the third most common type of malignancy in the developed western world and the third leading cause of mortality from cancer in the United States (1). Although the incidence of CRC varies by 20 -fold worldwide, in Jordan, CRC is the most common type of cancer in males and the second following breast cancer in females (2). Although the

Correspondence to: Dr Nizar M. Mhaidat, Department of Clinical Pharmacy, Faculty of Pharmacy, Jordan University of Science and Technology, Ramtha Street, Irbid 22110, Jordan

E-mail: nizarm@just.edu.jo

Key words: colon cancer, paclitaxel, unfolded protein response, glucose-regulated protein 78, Mcl-1, apoptosis survival rate following excision of the primary tumor is high, when the disease spreads to distant sites, it is usually incurable by current systemic treatment options, including chemotherapy, radiotherapy and immunotherapy. This is hypothesized to be largely due to resistance of cancer cells to induction of programmed cell death or apoptosis. Understanding and overcoming resistance mechanism(s) of cancer cells to apoptosis may simplify the identification of novel therapeutic targets and development of new treatment options.

Taxanes, including paclitaxel and docetaxel are an essential class of chemotherapeutic agents that exert anticancer effects in vitro and in vivo against a number of types of cancer, including lung, ovary, breast, and head and neck cancer (3). The two taxanes were isolated from the bark of the American Yew (Taxus brevifolia) and later semi-synthesized from the foliage and seeds of European Yew (Taxus baccata). Initially, taxanes were described as antimitotic agents that bind to $\beta$-tubulin, stabilize the microtubule polymer and protect it from disassembly, which differs from other tubulin-targeted agents, including colchicine that inhibit microtubule assembly resulting in blockage of the cell cycle at the G2/M phase and cell apoptosis $(4,5)$.

A number of mechanisms were proposed to explain cancer cell resistance to taxanes, one of which is the over-expression of P-glycoprotein which induces efflux of the drug $(6,7)$. Another reported mechanism that leads to cancer cell resistance is the ability of taxanes to activate numerous prosurvival signaling pathways, including the Ras-Raf-MEK-ERK pathway (8-10).

The mitogen-activated protein kinases (MAPKs) are a family of intracellular enzymes that comprise essential mediators of signal transduction pathways and organize the cell response to different extracellular stimuli $(11,12)$. The MAPK family comprises three major MAP kinase groups: extracellular signal-regulated kinase (Erk1 and 2); c-Jun N-terminal kinases (JNK 1, 2 and 3) and p38 MAPK (p38 $\alpha$, $\beta, \delta$ and $\gamma$ (13). Phosphorylation of MAPK by MAPK kinase leads to its activation, each MAPK is activated by specific MEK-protein kinase and individual MAPKs regulate distinct cell processes involved in cell division, differentiation and survival. The Ras-MEK-ERK pathway is associated with suppression of apoptosis, while stress-activated kinases are associated with the induction of apoptosis. ERK1/2 is located downstream of a group of kinases, including protein kinase $\mathrm{C}$ (PKC), MEK1 and Raf-1. When stimulated by extracellular signals, the kinases are phosphorylated, leading to their 
activation. Ras/Raf/MEK/ERK signaling activation is a hallmark of various types of cancer, including breast, lung and colorectal cancer as well as melanoma (14). Moreover, previous studies have reported that variation in the composition and $\beta$-tubulin isotype mutations, may lead to cancer cell resistance to taxanes (15-17). Previously, it was shown that the unfolded protein response (UPR), evident by the expression of endoplasmic reticulum (ER) chaperone glucose-regulated protein 78 (GRP78), contributes to the antiapoptotic effects and resistance to chemotherapy in a number of types of cancer $(18,19)$.

Caffeine (1,3,7-trimethylxanthine) is a natural stimulatory substance that is commonly present in a number of sources, including leaves of tea, coffee beans, cocoa beverages, soft drinks and even in chocolate products (20). Caffeine is also available in a number of over-the-counter (OTC) remedies, including some pain killers (21). Due to its frequent and common consumption, caffeine may be considered the most frequently ingested neuroactive compound $(22,23)$. Previous studies have reported several effects of caffeine, including the suppression of cell proliferation (24), enhancement of radiation and anticancer agents toxicity, as well as the elimination of chemical- or radiation-induced delays in cell cycle progression $(25,26)$. Caffeine is potentially capable of inhibiting ultraviolet B-induced skin cancer in mice $(27,28)$ and a study by Nomura et al (29) showed that caffeine $(0.5 \mathrm{mM})$ may inhibit malignant cell transformation induced by epidermal growth factor. Caffeine has been the subject of intensive studies due to various effects reported, including the effect of caffeine on cell cycle function, the ability to induce apoptosis and affecting specific regulatory proteins, including p53 (30-32). In the current study, the effect of caffeine on paclitaxel-induced cytotoxicity was investigated in CRC cell lines. In addition, possible molecular targets for this effect were evaluated.

\section{Materials and methods}

Cell lines, antibodies and other reagents. The human colon cancer cell line Colo205, was cultured in DMEM containing 10\% FCS (BioWhittaker, Verviers, Belgium).

Paclitaxel was purchased from Sigma-Aldrich (St. Louis, MO, USA) and stored as a $20 \mathrm{mM}$ solution in dimethyl sulfoxide (DMSO) with a final concentration of $0.1 \%(\mathrm{v} / \mathrm{v})$ at $-80^{\circ} \mathrm{C}$ and diluted with DMEM medium prior to use. Propidium iodide (PI) was purchased from Sigma-Aldrich. The rabbit polyclonal antibody against ERK1/2 was purchased from Cell Signalling Technology (Beverly, MA, USA). The ERK1/2 inhibitor (MEK Inhibitor, U0126) was purchased from Calbiochem (La Jolla, CA, USA). Phosphorylated ERK1/2, the rabbit MAbs against GRP78/Bip and Mcl-1 antibodies were all purchased from Santa Cruz Biotechnology, Inc. (Santa Cruz, CA, USA).

Apoptosis. Quantification of apoptotic cells by measurement of sub-G1 DNA content using the PI method was carried out as described in a previous study (17).

Western blot and protein expression analysis. Cells were cultured to $80 \%$ confluency. The cells were trypsinised and washed with medium twice followed by one cold PBS wash.

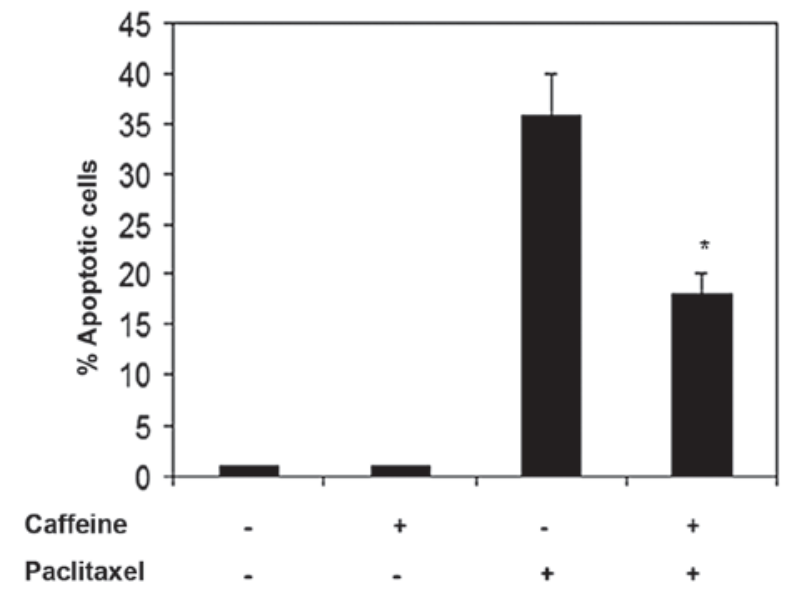

Figure 1. Effect of caffeine on paclitaxel-induced cell apoptosis. Colo205 cells were pretreated with or without caffeine for $2 \mathrm{~h}$ prior to the addition of paclitaxel for a further $48 \mathrm{~h}$. Apoptosis was assessed by measurement of sub-G1 DNA content using the PI method in flow cytometry. The data show the mean \pm SE of three individual experiments. PI, propidium iodide.

The cells were lysed with a Triton X-100 based lysis buffer [10\% Triton X-100, 10\% glycerol, $150 \mathrm{mM} \mathrm{NaCl}, 20 \mathrm{mM}$ Tris $(\mathrm{pH}=7.5), 2 \mathrm{mM}$ ethylene diamine tetraacetic acid (EDTA), $1 \mathrm{mM}$ phenylmethylsulphonyl fluoride (PMSF), $10 \times 10^{-6} \mathrm{~g}$ aprotinin and $10 \times 10^{-6} \mathrm{~g}$ leupeptin]. Cell lysates were transferred into microcentrifuge tubes and following $1 \mathrm{~h}$ on ice were centrifuged at $4,500 \mathrm{xg}$ for $30 \mathrm{~min}$ at $40^{\circ} \mathrm{C}$. The protein content of cell extracts was determined by the Bradford assay (Bio-Rad, Hercules, CA, USA). A total of 20-30 $\mu \mathrm{g}$ of protein was electrophoresed on 10-15\% SDS-PAGE gels and transferred to nitrocellulose membranes. The membranes were blocked, incubated with primary Abs at the appropriate concentration and subsequently incubated with horseradish peroxidase-conjugated goat anti-rabbit IgG or goat anti-mouse IgG (1:3,000 dilutions; Bio-Rad). Labeled bands were detected by an Immun-Star ${ }^{\mathrm{TM}}$ HRP Chemiluminescent kit and images were captured. The intensity of the bands was quantified with the Bio-Rad VersaDoc ${ }^{\mathrm{TM}}$ image system. The relative expression of specific proteins was determined by dividing the densitometric value of the test protein by that of the control (GAPDH).

Statistical analysis. Data are expressed as mean \pm SE. The statistical significance of intergroup differences in normally distributed continuous variables was determined using a Student's t-test. $\mathrm{P} \leq 0.05$ was considered to indicate a statistically significant difference.

\section{Results}

Caffeine does not induce apoptosis of CRC cells and antagonizes paclitaxel-induced apoptosis. To study the effect of caffeine on paclitaxel-induced apoptosis of CRC cells, Colo205 cells were first treated with different doses of caffeine. Dose titration of caffeine $(0-20 \mu \mathrm{M})$ was performed and results indicated that caffeine did not induce apoptosis of Colo205 cells (data not shown). The combination effect of caffeine and paclitaxel against Colo205 cells was evaluated (Fig. 1). Results 


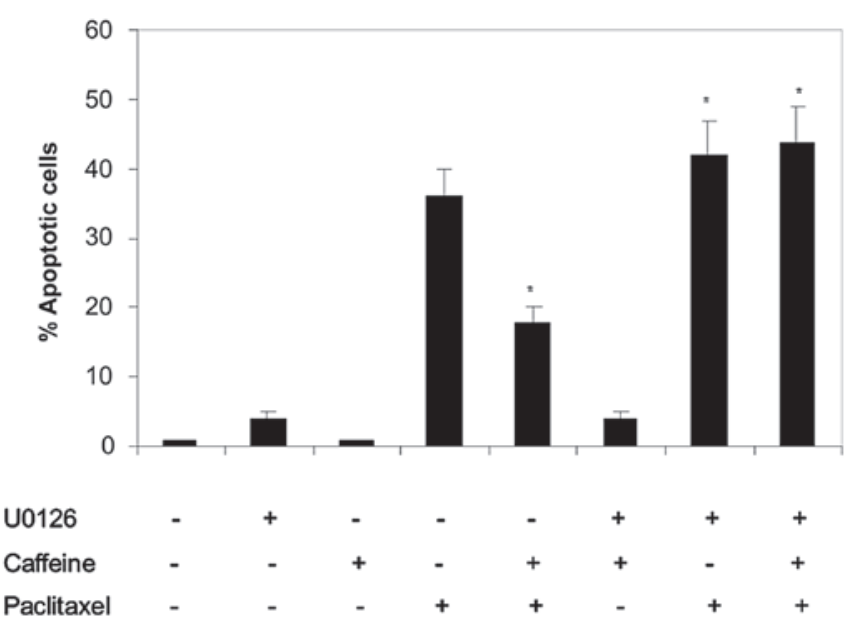

Figure 2. Caffeine antagonizes paclitaxel-induced cell apoptosis by activation of the MEK-ERK pathway. Colo205 cells were pretreated with or without the MEK chemical inhibitor, U0126, for $2 \mathrm{~h}$ prior to the addition of caffeine for another $2 \mathrm{~h}$. Paclitaxel was added for a further $48 \mathrm{~h}$. Apoptosis was assessed by measurement of sub-G1 DNA content using the PI method in flow cytometry. The data present the mean \pm SE of three individual experiments. MEK, mitogen-activated protein/extracellular signal-regulated kinase.

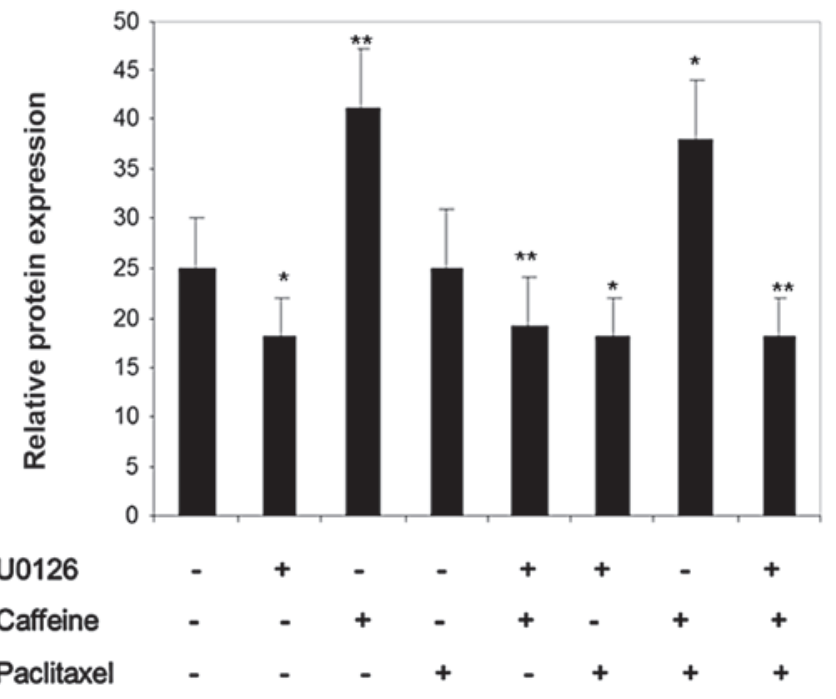

Figure 3. Relative $\mathrm{MCl}-1$ protein expression following treatment with the chemical inhibitor of MEK (U0126), caffeine and paclitaxel alone or in combination. Colo205 cells were pretreated with or without the MEK chemical inhibitor, U0126, for $2 \mathrm{~h}$ prior to the addition of caffeine for a further $2 \mathrm{~h}$. Paclitaxel was added for another $48 \mathrm{~h}$. Whole-cell lysates were subjected to western blot analysis. Relative expression was determined against control protein (GAPDH) using densitometric analysis. MEK, mitogen-activated protein/extracellular signal-regulated kinase.

showed that pretreatment of Colo205 cells with caffeine at $20 \mu \mathrm{M}$, prior to the addition of paclitaxel at $80 \mu \mathrm{M}$, significantly inhibited paclitaxel-induced apoptosis.

Caffeine induces the MEK/ERK survival pathway. A previous study showed that paclitaxel induces activation of the MEK/ERK survival pathway (17). To gain a better understanding of whether pretreatment with caffeine was responsible for antagonism of paclitaxel-induced apoptosis by further increasing activation of ERK1/2 pathway, Colo205

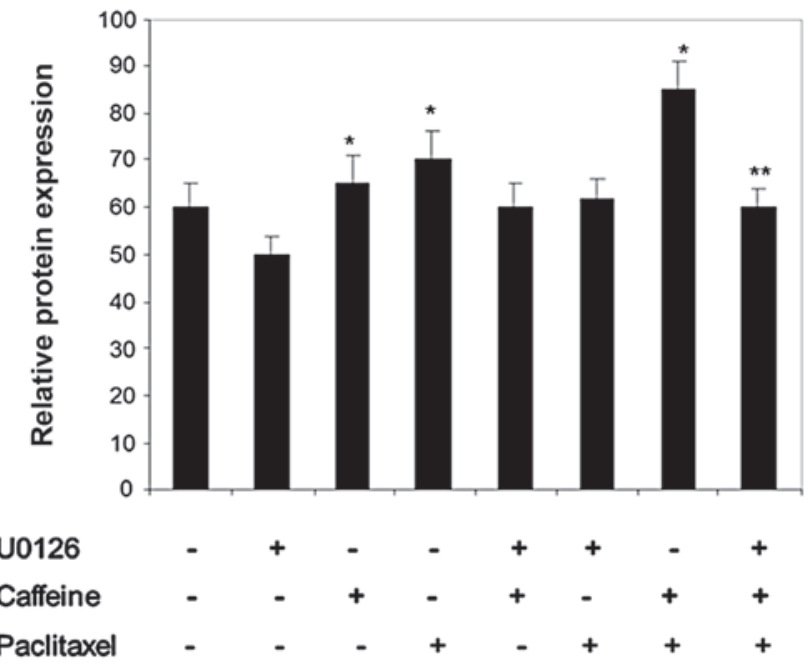

Figure 4. Relative GRP78 protein expression following treatment with the chemical inhibitor of MEK (U0126), with or without caffeine and paclitaxel alone. Whole-cell lysates were subjected to western blot analysis. Relative expression was determined against control protein (GAPDH) using densitometric analysis. MEK, mitogen-activated protein/extracellular signal-regulated kinase. cells were pretreated with the chemical inhibitor of MEK, U0126, prior to the addition of caffeine and paclitaxel. Results in Fig. 2 show that when the MEK-ERK pathway is inhibited, caffeine does not reverse paclitaxel-induced cytotoxicity, indicating that such antagonism may be mediated by activation of the MEK-ERK survival pathway.

Caffeine induces Mcl-1 and GRP78 protein levels but not survivin. To study whether caffeine-paclitaxel combination-induced activation of MEK-ERK signaling may be influencing other cell survival mediators, alterations in the protein levels of Mcl-1, GRP78 and the inhibitor of apoptosis protein, survivin, were evaluated in Colo205 cells following various treatments. Results in Figs. 3-5 showed that treatment of Colo205 cells with caffeine induced levels of Mcl-1 and GRP78, respectively, but not survivin. Treatment with paclitaxel induced protein expression of GRP78 and surviving, however, this was not observed to be significant. Levels of Mcl-1 were not affected by paclitaxel treatment. Pretreatment of cells with caffeine followed by paclitaxel resulted in a significant increase in all proteins, particularly GRP78 and Mcl-1. This increase was almost completely abrogated by pretreatment with the chemical inhibitor, U0126, indicating that MEK-ERK signaling occurs upstream of caffeine and paclitaxel-induced GRP78 and Mcl-1 upregulation.

\section{Discussion}

The aim of the present study was to evaluate the effect of caffeine on the cytotoxicity induced by paclitaxel on CRC cells. The aforementioned results reveal that sensitivity of CRC cells to paclitaxel may be reversed with pretreatment of caffeine. This is largely mediated by upregulation of the antiapoptotic mediators Mcl-1 and GRP78, but not survivin.

It has been previously shown that paclitaxel induces UPR in CRC as observed by upregulation of the UPR master marker 


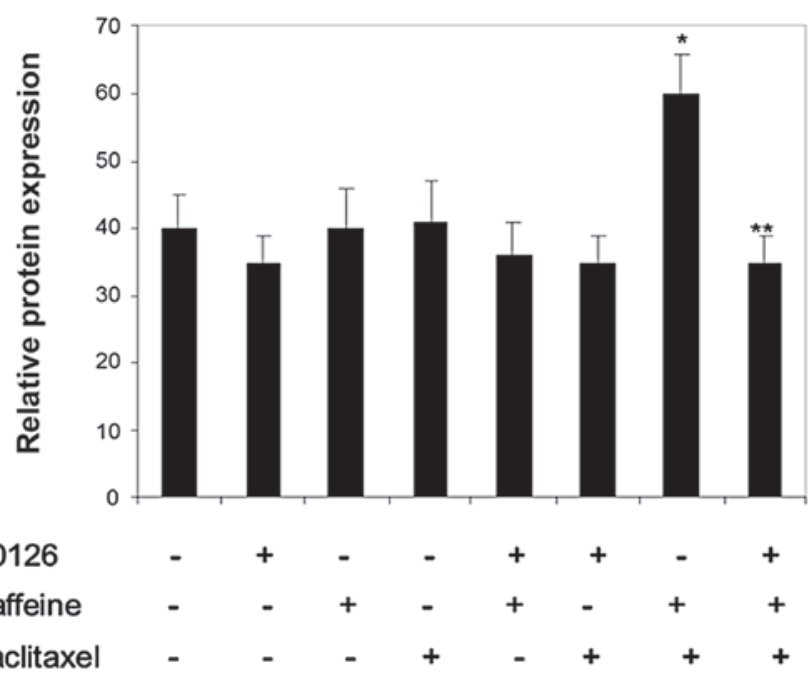

Figure 5. Relative survivin protein expression following treatment with the chemical inhibitor of MEK (U0126), with or without caffeine and paclitaxel. Whole-cell lysates were subjected to western blot analysis Relative expression was determined against the control protein (GAPDH) using densitometric analysis. MEK, mitogen-activated protein/extracellular signal-regulated kinase.

GRP78 and phosphorylation of eukaryotic initiation factor $2 \alpha$ subunit (33). The UPR is essential for eukaryotic cell survival under ER stress and normal growth conditions. To ensure that the ER protein-folding capacity is not overwhelmed, the UPR is activated to remove the stress condition forced on the ER and is organized by transcriptional activation of a number of genes mediated by IRE1 and ATF6, a general reduction in translation initiation and selective translation of specific mRNAs mediated by PERK (34). However, if ER stress remains unresolved, UPR may induce apoptotic cell death by activation of various molecules, including caspases- 4 and -12 and Bax/Bak $(35,36)$. Thus, the mechanism of chemoresistance of CRC cells to paclitaxel-induced apoptosis may be the activation of UPR.

Caffeine is known to differentially modify the cytotoxicity of specific chemotherapeutic agents. This is hypothesized to be due to DNA intercalation (37), inhibition of poly (ADP ribose) polymerase (38) and cAMP phosphodiesterase (39). Caffeine was shown to increase the cytotoxic effect of cisplatin, a DNA damaging agent, against lymphoma cells (40) and that of etoposide on HeLa cervical carcinoma cells (41). These effects were associated with the potential of caffeine to induce cell cycle arrest, particularly at the G2/M phase, which was followed by apoptosis $(25,40,41)$. In addition, caffeine has been shown to enhance paclitaxel-induced apoptosis in human breast cancer MCF-7 cells (25). By contrast, caffeine inhibited paclitaxel-induced apoptosis of lung cancer cells by suppression of the effect of paclitaxel on cell cycle distribution (42). In agreement with this, the results of the current study showed that caffeine antagonizes paclitaxel-induced cytotoxicity in Colo205.

To elucidate the mechanism by which caffeine prevents CRC cell sensitivity to paclitaxel, protein levels of GRP78 were evaluated. Results indicated that caffeine induces GRP78. These findings were consistent with previous studies, indicating that treatment of condrocytes with caffeine induces ER stress and increase intracellular calcium levels $(43,44)$ thus disturbing ER function and inducing UPR.

Furthermore, apoptosis mediated through the mitochondrial pathway and ER has been shown to be regulated by the Bcl-2 family proteins $(45,46)$. Antiapoptotic family members, including $\mathrm{Bcl}-\mathrm{XL}, \mathrm{Bcl}-2$ and $\mathrm{Mcl}-1$ protect mitochondrial integrity, while the proapoptotic proteins in the family encourage the release of apoptogenic proteins, including cytochrome $c$, Smac/DIABLO and AIF from the mitochondria and calcium from the ER $(45,46)$. Among the resistance mechanisms to paclitaxel in several types of cancer, including melanoma, breast and prostate cancers, is the upregulation of the antiapoptotic Bcl-2 family protein Mcl-1 $(47,48)$. Results of this study have demonstrated that the treatment of Colo205 cells with caffeine increases the protein levels of Mcl-1 indicating that caffeine contributes to paclitaxel-induced apoptosis, at least in part, by induction of the Mcl-1 levels.

Another important class of proteins that is involved in the regulation of apoptosis are the inhibitor of apoptosis proteins (IAPs). This family includes IAP 1 and 2, XIAP, ML-IAP and survivin. In general, they bind to caspases and inhibit their activation (caspase-9) or prevent their effector action (caspases 3 and 7). Results of previous studies have shown that paclitaxel does not induce the expression of survivin, however, the inhibition of survivin may sensitize cancer cells to paclitaxel-induced cytotoxicity (49). In agreement with this, the present results have demonstrated that treatment of Colo205 cells with either paclitaxel or caffeine did not induce protein levels of survivin but treatment with a combination of paclitaxel and caffeine has significantly increased survivin levels. The cause of this result remains to be elucidated in future studies.

Findings of previous studies have demonstrated that members of Bcl-2 proteins and IAP may be transcriptional targets of the MEK-ERK pathway $(50,51)$. In the current study, caffeine treatment resulted in the upregulation of Mcl-1, but not survivin. Inhibition of the MEK-ERK pathway decreased the caffeine-induced levels of Mcl-1. This finding may contribute to the role of caffeine in protecting Colo205 cells from paclitaxel-induced killing by stabilizing the mitochondrial and ER membranes via the upregulation of Mcl-1 expression, preventing the release of apoptotic molecules. This is hypothesized to occur by promoting the binding of Mcl-1 to proapoptotic BH3-only members, including Bid, Bim and Noxa (52-56).

In summary, the current observations indicated that caffeine may prevent paclitaxel-induced apoptosis, most likely by activation of the MEK-ERK signaling pathway. This activation has led to an increase in levels of Mcl-1 and GRP78 that were capable of protecting against the paclitaxel cytotoxic effect by stabilizing mitochondria and ER membranes, thus inhibiting release of apoptogenic molecules.

\section{Acknowledgements}

The authors would like to acknowledge the Jordan University of Science and Technology, Irbid, Jordan, for financial support (grant no. 230-2010). 


\section{References}

1. Jemal A, Siegel R, Ward E, et al: Cancer statistics, 2008. CA Cancer J Clin 58: 71-96, 2008.

2. Al-Tarawneh M, Khatib S and Arqub K: Cancer incidence in Jordan, 1996-2005. East Mediterr Health J 16: 837-845, 2010.

3. Rowinsky EK and Donehower RC: Paclitaxel (taxol). N Engl J Med 332: 1004-1014, 1995.

4. Gonçalves A, Braguer D, Carles G, André N, Prevôt C and Briand C: Caspase-8 activation independent of CD95/CD95-L interaction during paclitaxel-induced apoptosis in human colon cancer cells (HT29-D4). Biochem Pharmacol 60: 1579-1584, 2000

5. Bhalla KN: Microtubule-targeted anticancer agents and apoptosis. Oncogene 22: 9075-9086, 2003.

6. Childs S, Yeh RL, Hui D and Ling V: Taxol resistance mediated by transfection of the liver-specific sister gene of P-glycoprotein. Cancer Res 58: 4160-4167, 1998.

7. Lecureur V, Sun D, Hargrove P, et al: Cloning and expression of murine sister of P-glycoprotein reveals a more discriminating transporter than MDR1/P-glycoprotein. Mol Pharmacol 57: $24-35,2000$

8. Subbaramaiah K, Hart JC, Norton L and Dannenberg AJ: Microtubule-interfering agents stimulate the transcription of cyclooxygenase-2. Evidence for involvement of ERK1/2 and p38 mitogen-activated protein kinase pathways. J Biol Chem 275 : $14838-14845,2000$.

9. McDaid HM and Horwitz SB: Selective potentiation of paclitaxel (taxol)-induced cell death by mitogen-activated protein kinase kinase inhibition in human cancer cell lines. Mol Pharmacol 60 290-301, 2001

10. Mhaidat NM, Thorne RF, Zhang XD and Hersey P: Regulation of docetaxel-induced apoptosis of human melanoma cells by different isoforms of protein kinase C. Mol Cancer Res 5: 1073-1081, 2007

11. Troppmair J, Bruder JT, Munoz H, et al: Mitogen-activated protein kinase/extracellular signal-regulated protein kinase activation by oncogenes, serum, and 12-O-tetradecanoylphorbol-13-acetate requires Raf and is necessary for transformation. J Biol Chem 269: 7030-7035, 1994

12. Hommes DW, Peppelenbosch MP and van Deventer SJ: Mitogen activated protein (MAP) kinase signal transduction pathways and novel anti-inflammatory targets. Gut 52: 144-151, 2003

13. Davis RJ: Signal transduction by the JNK group of MAP kinases Cell 103: 239-252, 2000

14. Alessi DR, Saito Y, Campbell DG, et al: Identification of the sites in MAP kinase kinase-1 phosphorylated by p74raf-1. EMBO J 13 1610-1619, 1994.

15. Kavallaris M, Kuo DY, Burkhart CA, et al: Taxol-resistant epithelial ovarian tumors are associated with altered expression of specific beta-tubulin isotypes. J Clin Invest 100: 1282-1293, 1997.

16. Ranganathan S, Benetatos CA, Colarusso PJ, Dexter DW and Hudes GR: Altered beta-tubulin isotype expression in paclitaxel-resistant human prostate carcinoma cells. Br J Cancer 77: 562-566, 1998

17. Mhaidat NM, Thorne R, Zhang XD and Hersey P: Involvement of endoplasmic reticulum stress in Docetaxel-induced JNK-dependent apoptosis of human melanoma. Apoptosis 13 1505-1512, 2008.

18. Lee AS: GRP78 induction in cancer: therapeutic and prognostic implications. Cancer Res 67: 3496-3499, 2007.

19. Ma Y and Hendershot LM: ER chaperone functions during normal and stress conditions. J Chem Neuroanat 28: 51-65, 2004

20. Wierzejska R: Caffeine - common ingredient in a diet and its influence on human health. Rocz Panstw Zakl Hig 63: 141-147, 2012 (In Polish)

21. Tavares C and Sakata RK: Caffeine in the treatment of pain. Rev Bras Anestesiol 62: 387-401, 2012

22. Roehrs T and Roth T: Caffeine: sleep and daytime sleepiness. Sleep Med Rev 12: 153-162, 2008.

23. Glade MJ: Caffeine-not just a stimulant. Nutrition 26: 932-938, 2010.

24. Okano J, Nagahara T, Matsumoto K and Murawaki Y: Caffeine inhibits the proliferation of liver cancer cells and activates the MEK/ERK/EGFR signalling pathway. Basic Clin Pharmacol Toxicol 102: 543-551, 2008 .

25. Saunders DE, Lawrence WD, Christensen C, Wappler NL, Ruan H and Deppe G: Paclitaxel-induced apoptosis in MCF-7 breast-cancer cells. Int J Cancer 70: 214-220, 1997.
26. Ribeiro JC, Barnetson AR, Jackson P, Ow K, Links M and Russell PJ: Caffeine-increased radiosensitivity is not dependent on a loss of G2/M arrest or apoptosis in bladder cancer cell lines. Int J Radiat Biol 75: 481-492, 1999.

27. Lu YP, Lou YR, Lin Y, et al: Inhibitory effects of orally administered green tea, black tea, and caffeine on skin carcinogenesis in mice previously treated with ultraviolet B light (high-risk mice): relationship to decreased tissue fat. Cancer Res 61: 5002-5009, 2001.

28. Lu YP, Lou YR, Peng QY, Xie JG and Conney AH: Stimulatory effect of topical application of caffeine on UVB-induced apoptosis in the epidermis of $\mathrm{p} 53$ and Bax knockout mice. Cancer Res 64: 5020-5027, 2004.

29. Nomura M, Ichimatsu D, Moritani S, et al: Inhibition of epidermal growth factor-induced cell transformation and Akt activation by caffeine. Mol Carcinog 44: 67-76, 2005.

30. He Z, Ma WY, Hashimoto T, Bode AM, Yang CS and Dong Z: Induction of apoptosis by caffeine is mediated by the p53, Bax, and caspase 3 pathways. Cancer Res 63: 4396-4401, 2003.

31. Hashimoto T, He Z, Ma WY, et al: Caffeine inhibits cell proliferation by G0/G1 phase arrest in JB6 cells. Cancer Res 64: 3344-3349, 2004.

32. Bode AM and Dong Z: The enigmatic effects of caffeine in cell cycle and cancer. Cancer Lett 247: 26-39, 2007.

33. Mhaidat NM, Alali FQ, Matalqah SM, et al: Inhibition of MEK sensitizes paclitaxel-induced apoptosis of human colorectal cancer cells by downregulation of GRP78. Anticancer Drugs 20: 601-606, 2009.

34. Zhang K and Kaufman RJ: Protein folding in the endoplasmic reticulum and the unfolded protein response. Handb Exp Pharmacol 69-91, 2006.

35. Szegezdi E, Logue SE, Gorman AM and Samali A: Mediators of endoplasmic reticulum stress-induced apoptosis. EMBO Rep 7: 880-885, 2006

36. Tabas I and Ron D: Integrating the mechanisms of apoptosis induced by endoplasmic reticulum stress. Nat Cell Biol 13: 184-190, 2011.

37. Lyles MB and Cameron IL: Caffeine and other xanthines as cytochemical blockers and removers of heterocyclic DNA intercalators from chromatin. Cell Biol Int 26: 145-154, 2002.

38. Geraets L, Moonen HJ, Wouters EF, Bast A and Hageman GJ: Caffeine metabolites are inhibitors of the nuclear enzyme poly(ADP-ribose)polymerase-1 at physiological concentrations. Biochem Pharmacol 72: 902-910, 2006

39. Howell LL: Comparative effects of caffeine and selective phosphodiesterase inhibitors on respiration and behavior in rhesus monkeys. J Pharmacol Exp Ther 266: 894-903, 1993.

40. Shinomiya N, Shinomiya M, Wakiyama H, Katsura Y and Rokutanda M: Enhancement of CDDP cytotoxicity by caffeine is characterized by apoptotic cell death. Exp Cell Res 210: 236-242, 1994.

41. Lock RB, Galperina OV, Feldhoff RC and Rhodes LJ: Concentration-dependent differences in the mechanisms by which caffeine potentiates etoposide cytotoxicity in HeLa cells Cancer Res 54: 4933-4939, 1994

42. Kitamoto Y, Sakurai H, Mitsuhashi N, Akimoto T and Nakano T: Caffeine diminishes cytotoxic effects of paclitaxel on a human lung adenocarcinoma cell line. Cancer Lett 191: 101-107, 2003

43. Zhang PL, Lun M, Teng J, et al: Preinduced molecular chaperones in the endoplasmic reticulum protect cardiomyocytes from lethal injury. Ann Clin Lab Sci 34: 449-457, 2004.

44. Ostergaard L, Simonsen U, Eskildsen-Helmond Y, et al: Proteomics reveals lowering oxygen alters cytoskeletal and endoplasmatic stress proteins in human endothelial cells. Proteomics 9: 4457-4467, 2009.

45. Martinou JC and Green DR: Breaking the mitochondrial barrier. Nat Rev Mol Cell Biol 2: 63-67, 2001.

46. Adams JM and Cory S: The Bcl-2 protein family: arbiters of cell survival. Science 281: 1322-1326, 1998.

47. Ding Q, Huo L, Yang JY, et al: Down-regulation of myeloid cell leukemia-1 through inhibiting Erk/Pin 1 pathway by sorafenib facilitates chemosensitization in breast cancer. Cancer Res 68: 6109-6117, 2008

48. Wesarg E, Hoffarth S, Wiewrodt R, et al: Targeting BCL-2 family proteins to overcome drug resistance in non-small cell lung cancer. Int J Cancer 121: 2387-2394, 2007.

49. Wang Z, Xie Y and Wang H: Changes in survivin messenger RNA level during chemotherapy treatment in ovarian cancer cells. Cancer Biol Ther 4: 716-719, 2005. 
50. Boucher MJ, Morisset J, Vachon PH, Reed JC, Lainé J and Rivard N: MEK/ERK signaling pathway regulates the expression of Bcl-2, Bcl-X(L), and Mcl-1 and promotes survival of human pancreatic cancer cells. J Cell Biochem 79: 355-369, 2000.

51. Hu P, Han Z, Couvillon AD and Exton JH: Critical role of endogenous Akt/IAPs and MEK1/ERK pathways in counteracting endoplasmic reticulum stress-induced cell death. J Biol Chem 279: 49420-49429, 2004.

52. Wang YF, Jiang CC, Kiejda KA, Gillespie S, Zhang XD and Hersey P: Apoptosis induction in human melanoma cells by inhibition of MEK is caspase-independent and mediated by the Bcl-2 family members PUMA, Bim, and Mcl-1. Clin Cancer Res 13: 4934-4942, 2007.
53. O'Connor L, Strasser A, O'Reilly LA, et al: Bim: a novel member of the Bcl-2 family that promotes apoptosis. EMBO J 17: 384-395, 1998.

54. Cheng EH, Wei MC, Weiler S, et al: BCL-2, BCL-X(L) sequester $\mathrm{BH} 3$ domain-only molecules preventing BAX-and BAK-mediated mitochondrial apoptosis. Mol Cell 8: 705-711, 2001.

55. Korsmeyer SJ, Wei MC, Saito M, Weiler S, Oh KJ and Schlesinger PH: Pro-apoptotic cascade activates BID, which oligomerizes BAK or BAX into pores that result in the release of cytochrome $c$. Cell Death Differ 7: 1166-1173, 2000.

56. Bouillet P, Purton JF, Godfrey DI, et al: BH3-only Bcl-2 family member Bim is required for apoptosis of autoreactive thymocytes. Nature 415: 922-926, 2002. 